\title{
Effects of Home Confinement for COVID-19 on the Psychological Health and the Social Lifestyles of the People of the Kingdom of Saudi Arabia
}

\author{
Wissal Boughattas ${ }^{1}$, Mona Tolba ${ }^{2}$ \\ ${ }^{1}$ Department of Sport's Sciences, College of Education, Taif University, Taif, Saudi Arabia \\ ${ }^{2}$ Department of Special Education, College of Education, Taif University, Taif, Saudi Arabia \\ Email: weboughattas@tu.edu.sa
}

How to cite this paper: Boughattas, W., \& Tolba, M. (2021). Effects of Home Confinement for COVID-19 on the Psychological Health and the Social Lifestyles of the People of the Kingdom of Saudi Arabia. Psychology, 12, 1141-1152.

https://doi.org/10.4236/psych.2021.127070

Received: July 3, 2021

Accepted: July 26, 2021

Published: July 29, 2021

Copyright $\odot 2021$ by author(s) and Scientific Research Publishing Inc. This work is licensed under the Creative Commons Attribution International License (CC BY 4.0).

http://creativecommons.org/licenses/by/4.0/

(c) (i) Open Access

\begin{abstract}
In March 2020, the World Health Organization announced that the coronavirus has become a global pandemic that may cause death by infection. Consequently, radical measures were taken to limit the spread of this deadly virus. Public health authorities in the Kingdom of Saudi Arabia, mandated total confinement to limit the spread of the virus. These measures have brought about a fundamental change in people's daily lifestyles, especially their social lives. Consequently, home confinement has had impacts on psychological health as well. This study aims to evaluate the effects of home confinement on the people of various regions in the Kingdom of Saudi Arabia; we opted for a quantitative study design using an anonymous online survey. A total of 3589 subjects completed the "Scale of Social Lifestyle and Psychological Health for the COVID-19 Pandemic", which is a survey formulated for the purposes of this research. Results showed that confinement has changed the social lifestyles of the people in KSA, particularly for women and for people aged 30 to 50 years. For psychological health, statistically significant increases were observed in the levels of anxiety, depression, obsessive compulsive disorder, interpersonal sensitivity, and somatic symptoms, during quarantine. In conclusion, home confinement caused a radical change in the social lifestyles of the citizens of Saudi Arabia. Women, married people and those aged more than 50 years are more affected than others, the psychological impact was moderate to severe in terms of the assessed demographic variables.
\end{abstract}

\section{Keywords}

COVID-19, Psychological Health, Social Lifestyle, Confinement 


\section{Introduction}

In the year 2020, the COVID-19 disease, caused by a deadly virus that spreads at an incredible rate, rate, has affected the lives of people of all nations across the globe. This disease is now considered a new public health crisis (El-Gilany, 2021). To limit the spread of this virus, numerous countries around the world, including the Kingdom of Saudi Arabia (KSA), have taken a radical step for prevention: total confinement for a period ranging from one to three months or more (Wang et al., 2020a). In addition, different forms of "social distancing" measures-such as quarantine or confinement-were implemented as a strategy to slow the spread of the virus. This quarantine takes many forms, but in essence, its aim is to keep people away from each other and at home in order to reduce rates of spreading. This strategy has contained the virus and limited its damage, but has had other negative effects, in unemployment rates, in economic fallout, etc. ..., especially at the social and psychological levels. Confinement is based on very strict social distancing measures, pushing people to isolate themselves in their homes, away from their family and friends. The effects of quarantine manifested as changes in the social lifestyles of people worldwide, which involved reduced social interactions and family visits, which may be the reason for the increased sense of loneliness and isolation that people experienced, sometimes resulting in cases of depression and anxiety.

While preventive measures such as social distancing and quarantine were effective in slowing the spread of the deadly disease, they simultaneously had negative psychological impacts. The same recent study has highlighted this observation. The study by Lee \& Crunk (2020) confirms that people felt extreme fear and anxiety regarding prospects of infection and death. Brooks et al., (2020) explain that this stress resulted in increased cases of insomnia and other physical effects, which could potentially lead to depression and nervous breakdowns. Moreover, Brooks et al., (2020) affirm that infection of family members can contribute significantly to increased guilt, frustration and stress of the individual, resulting in rage and resentment. Furthermore, the result Torales et al., (2020) research's support that social distancing caused disorder in leisure and working hours, disruption of normal lifestyles, and stress throughout the population. As a consequence, anxiety, frustration, panic attacks, insomnia, depression, sleep disorders increased.

Recent study conducted a survey in the People's State of China (Wang et al., 2020b) a month after the coronavirus epidemic had spread to assess the psychological impact of the epidemic. The results confirmed that $53.8 \%$ of respondents assessed the psychological impact of the epidemic as being moderate or severe, $16.5 \%$ had symptoms of acute or mild depression, and $28.8 \%$ exhibited symptoms of intermediate-to-severe anxiety. The study found that these symptoms are more severe than SARS pandemic, which had impacted China 17 years prior. According to Zhai et al., (2020), isolation has had severe consequences on an individual's daily lifestyle and health leading to increased rates of acute and severe 
anxiety and depression.

In Arabic countries, same study (Ammar et al., 2020; Al-Fiqi \& Mohammad, 2020; Alfawaz et al., 2021) was published regarding the psychological consequences of social isolation. Specially that, social lifestyles form in these countries take a big part in the daily lives of individuals and are characterized by many aspects and phenomena stemming from the Arabic country's customs and traditions. The first and the second study, which was conducted in many Arabic countries, including Tunisia, Morocco, and Algeria, Ammar et al., (2020, 2021) support the risk of psychosocial stress during the quarantine period and the role of technology in promoting the isolation was assessed. The third study, identified the psychological issues caused by the coronavirus among Egyptian university students (Al-Fiqi \& Mohammad, 2020). The results found that anxiety and depression are the biggest psychological problems faced by university students in Egypt. The last study (Alfawaz et al., 2021), aims to discover the psychological well-being during COVID-19 lockdown from Saudi State University's Academic Community. The result shows that: 1) self-reported acute mental health disorders in Academic Community, and 2) the power of family, considerate as a coping mechanism, is essential for maintaining mental health, especially for women.

In the KSA, citizens' social lives are very active compared to other countries in the world; it is one where social exchanges and family visits are abundant regardless of whether there is a celebratory occasion or not. This social lifestyle is filled with warmth, love, and hospitality of all kinds. It contributes to the effective reduction of social isolation and the consequent psychological diseases. Additionally, Saudi Arabia's social lifestyle depends on the utilization of natural recreational areas such as parks, gardens, mountains, and the sea, shopping malls as well as travelling for tourism. It is obvious that this sudden change in the patterns of social life has had a significant impact on people and on various groups.

In this context, this study aimed to investigate whether there was an immediate impact of the COVID-19 pandemic on psychological health and on the social lifestyles of the Saudi people. We hypothesize that social distancing caused by confinement has caused a radical change in social lifestyles. We also suppose that quarantine has had a negative impact on the psychological health of the people of KSA, especially with regards to increased levels of anxiety and depression.

\section{Method}

\subsection{Study Design and Participant}

For this study, given the exceptional conditions, we opted for anonymous online questionnaires via social media (WhatsApp, Twitter, email) of people in different regions of Saudi Arabia. This choice allowed us to access as many participants as possible without having to move from a region to another. The online survey was disseminated to university teachers and students in different gover- 
norates of Saudi Arabia, after the commencement of home confinement, and they were encouraged to pass it on others.

\subsection{Material (Questionnaire)}

For this study, we formulated and utilized a scale named the Scale of Social Lifestyle and psychological Health for the COVID-19 (SLSPH-COVID-19), which transferred to an online survey link, distributed in the population vised by this study. We examine Content validity to ensure clarity of the questions. Numerous revisions were made to ameliorate the reliability and increase scientific value of the data to be collected. The reliability and validity of the survey was established by a pilot study ( $\mathrm{N}=82$ participants). The result shows a satisfactory Cronbach's a coefficient ( $>70 \%)$ for each section. The final version is constituted by three sections:

1) Demographic information: consists of general data (gender, age, level of education, residential location, marital status, employment status, and health status).

2) Social lifestyle: three principal axes (family lifestyle, social activity, social communication). The first two axes contain 4 items each one.

3) Psychological health: we adopted the psychological health questionnaire (Arabic version for symptomatic distress questionnaire, SCL test, (Abdel-Khalek, 2012) to the context of this study. Five axes, namely, anxiety (7 items), depression (5 items), obsessive compulsive disorder (5 items), interpersonal sensitivity (7 items), and somatic symptoms (7 items).

\subsection{Statistical Analysis}

All statistical analyses were performed using SPSS Statistic 20. Descriptive statistic was used to presented demographic variable: frequencies $(\mathrm{N})$ and percentages (\%), Chi-Square test were used to determine differences between categorical and continuous variables, to assess significant differences in means between groups (based on sociodemographic variable) during confinement period. For SLSPHCOVID-19, the responses were scored as 5, 4, 3, 2, and 1 for "Always", "Usually", "Sometimes", "Rarely", and "Never" respectively. Means for each axis were calculated to define the proportion of responses in terms with demographic variables. A score close to 5, for example, indicates decreases of means. A score close to 5, for example, indicates decreases of means. Linear regressions were used to estimate the associations between demographic variables characteristics and the different axes of the social life style questionnaire. $P$-value was considered significant at $p<0.05$.

\section{Result}

\subsection{Socio-Demographic Characteristics of Participants}

Table 1 shows that a total of 3589 subject (1860 were males, $43.6 \%$ and 1909 were females, 53.2\%) from 10 governorates of Saudi Arabia participate for this 
research. Participants' ages ranged from 18 to 65 years $(M=35.7$ SD $=5.88)$, with $53.2 \%$ identifying as female and $46.8 \%$ as male. Out of all the participants, $80 \%$ were married, $82.2 \%$ had higher qualifications, $41.3 \%$ was employee, and $35 \%$ reported being a student. Over $30 \%$ of the participants belonged the governorate of Makkah. Finally, 30\% of the participants reported having chronic health diseases. Also, there is no significant difference between the proportion of all sociodemographic variable.

Table 1. Socio-demographic characteristics of the participants.

\begin{tabular}{|c|c|c|c|c|}
\hline Variable & $\begin{array}{c}\text { All } \\
(3589)\end{array}$ & $\begin{array}{c}\text { Male } \\
1680(46.8)\end{array}$ & $\begin{array}{c}\text { Female } \\
1909(53.2)\end{array}$ & $P$-Value \\
\hline \multicolumn{4}{|l|}{ Ages (years) } & \multirow{5}{*}{0.71} \\
\hline $18-30$ & $1162(32.4)$ & $542(32.2)$ & $620(32.4)$ & \\
\hline & & & & \\
\hline $30-50$ & $1601(44.6)$ & $700(41.6)$ & $901(47.1)$ & \\
\hline$>50$ & $826(23)$ & $438(26.2)$ & $388(20.5)$ & \\
\hline \multicolumn{4}{|l|}{ Education level } & \multirow{3}{*}{0.43} \\
\hline Secondary school & $632(17.7)$ & $395(23.5)$ & $237(12.4)$ & \\
\hline Higher qualification & $2953(82.2)$ & $1285(76.5)$ & $1668(87.6)$ & \\
\hline \multicolumn{4}{|l|}{ Marital status } & \multirow{3}{*}{0.09} \\
\hline Married & $2875(80.1)$ & $1175(70)$ & $1700(89)$ & \\
\hline Divorced/ single & 704 (19.9) & $505(27.2)$ & $199(11)$ & \\
\hline \multicolumn{4}{|l|}{ Employment Status } & \multirow{5}{*}{0.23} \\
\hline Employee & $1482(41.3)$ & $902(72.8)$ & $797(41.7)$ & \\
\hline & & & & \\
\hline Student & $1253(35)$ & $456(27.2)$ & $645(33.8)$ & \\
\hline Other (retired/ none) & $854(23.7)$ & $322(19.1)$ & $467(22.5)$ & \\
\hline \multicolumn{4}{|l|}{ Health status } & \multirow{3}{*}{0.78} \\
\hline Chronic diseases & $1233(34)$ & $630(37.5)$ & $603(31.5)$ & \\
\hline No- Chronic diseases & $2356(66)$ & $1050(62.5)$ & $1306(68.5)$ & \\
\hline \multicolumn{4}{|l|}{ Region } & \multirow{5}{*}{0.12} \\
\hline $\begin{array}{l}\text { Makkah al mokaramah } \\
\text { (Taif/Makkah/Jeddah) }\end{array}$ & $1408(39.2)$ & $652(38.8)$ & $756(39.6)$ & \\
\hline Riayth & 970 & $575(34.2)$ & 395 (20.6) & \\
\hline $\begin{array}{c}\text { Madina mounawarah } \\
\text { (yanbu/Madina mounawarah) }\end{array}$ & $602(16.7)$ & $245(14.5)$ & $357(18.7)$ & \\
\hline Other region & $609(4.9)$ & $208(12.5)$ & $401(21.1)$ & \\
\hline
\end{tabular}

Note: Data represented as N (\%). 


\subsection{Impact of Confinement on Social Life Style (Family Life Style)}

Table 2 (part 1,2) show the result about the effect of convid-19 outbreak on social life style according to Socio-demographic variables. The majority of female participant (55\%) reported that they have changed their family life styles and their visit rarely family, friend's or neighbor during the covid-19 outbreak. This result indicates that family life style was significantly related to gender $(P>$ 0.05). The same result was generalized in regard to social activity $(76.6 \%$ for male) and social communication ( $83.7 \%$ for female). However, married participants and aged between 30 - 50 years were more affected by the COVID-19 confinement specially in family life style $(57.7 \%, 41.8 \%)$ and social activity $(70 \%$, $46 \%)$. Education level was also significantly associated with lifestyle changes among participants. People who have Higher qualification reported that they are more affected than the other category by confinement. They have changed all their life style (family, social activity and social communication). Other sociodemographic variables, including health status and employment status were significantly associated with questions regarding social activity.

Overall, the sociodemographic variable gender (female), age (participant aged 30 - 50 years), education level (participants who have higher qualification) was affected by the COVID-19 outbreak the other variables.

Table 2. (a) Changes in social life style by socio-demographic factors. (part 1); (b) Changes in social life style by demographic factors (part 2).

(a)

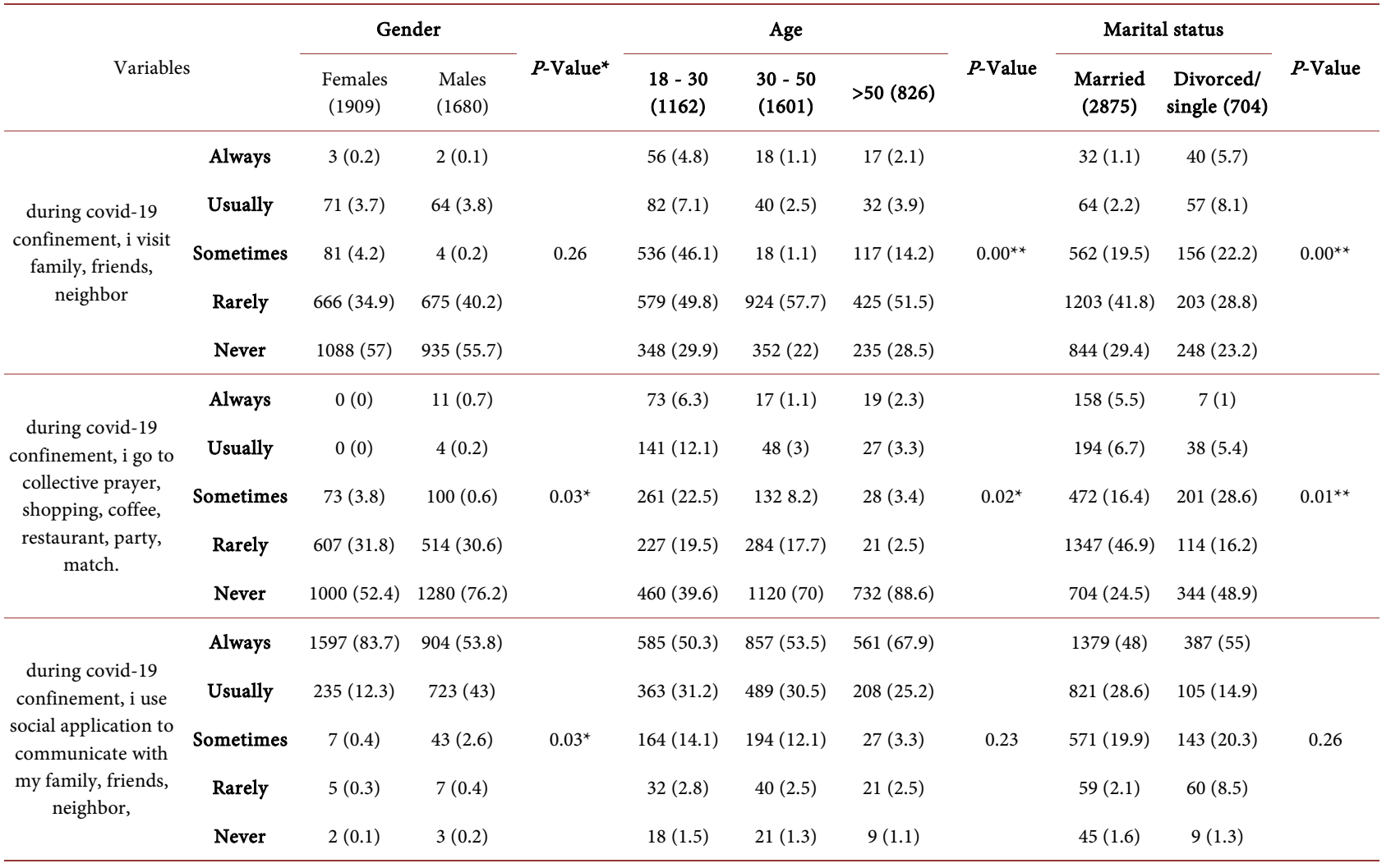


(b)

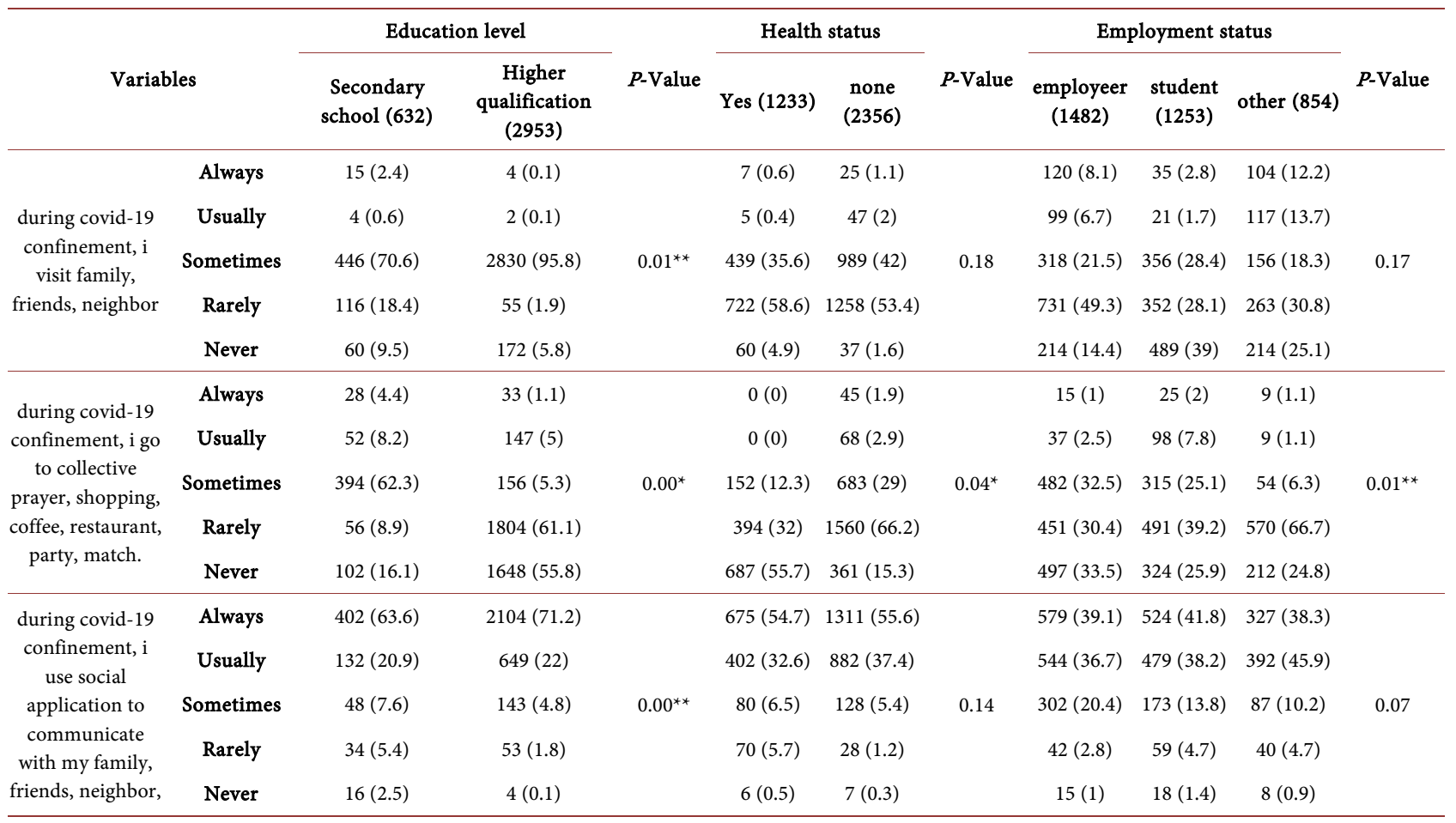

Note: Data represented as N (\%). P calculated by chi-square test to check the differences between males and females. $P<0.05$ is considered as significant.

\subsection{Sociodemographic Variables and Psychological Impact}

Table 3 presents the result of the association between sociodemographic variables and the psychological impact of the coronavirus disease outbreak. As this table indicates, there is a significant difference between the majority of the percentages according to different demographic variables. Female gender was significantly associated with higher scores in all psychological subscale, including in anxiety, $(B=0.30,95 \%$ Confidence Interval $95 \%$, CI 0.29 to 1.14), and depression ( $B=-0.52,95 \%$ Confidence Interval $95 \%$, CI 0.29 to 1.14 ). Age level was also significantly associated with higher scores in different psychological subscales. We note that the participant aged between (30 and 50) was significantly associated to anxiety and Sensitive efficacy. This result means thar this category of age presents a higher score of anxiety and Sensitive efficacy comparing with the other category. For the variable "marital status", married people were significantly associated with higher anxiety $\mathrm{B}=-0.22,95 \%$, CI: -0.20 to 0.63 ), obsessive-compulsive disorder ( $\mathrm{B}=0.25,95 \% \mathrm{CI}:-0.46$ to 0.89$)$ and Sensitive efficacy ( $\mathrm{B}=0.12$, 95\% Confidence Interval 95\%, CI, 0.01 to 0.23 ) subscales scores. However, the statical result specific to the sociodemographic variable (employment status) establish that the employees scores were significantly associated to anxiety and depression then student. Moreover, the people who don't have chronic disease present a higher score in depression, sensitive efficacy and Physical symptoms subscale then the people who have chronic diseases. The sociodemographic variable (level of education) was not associated with psychological subscale score. 


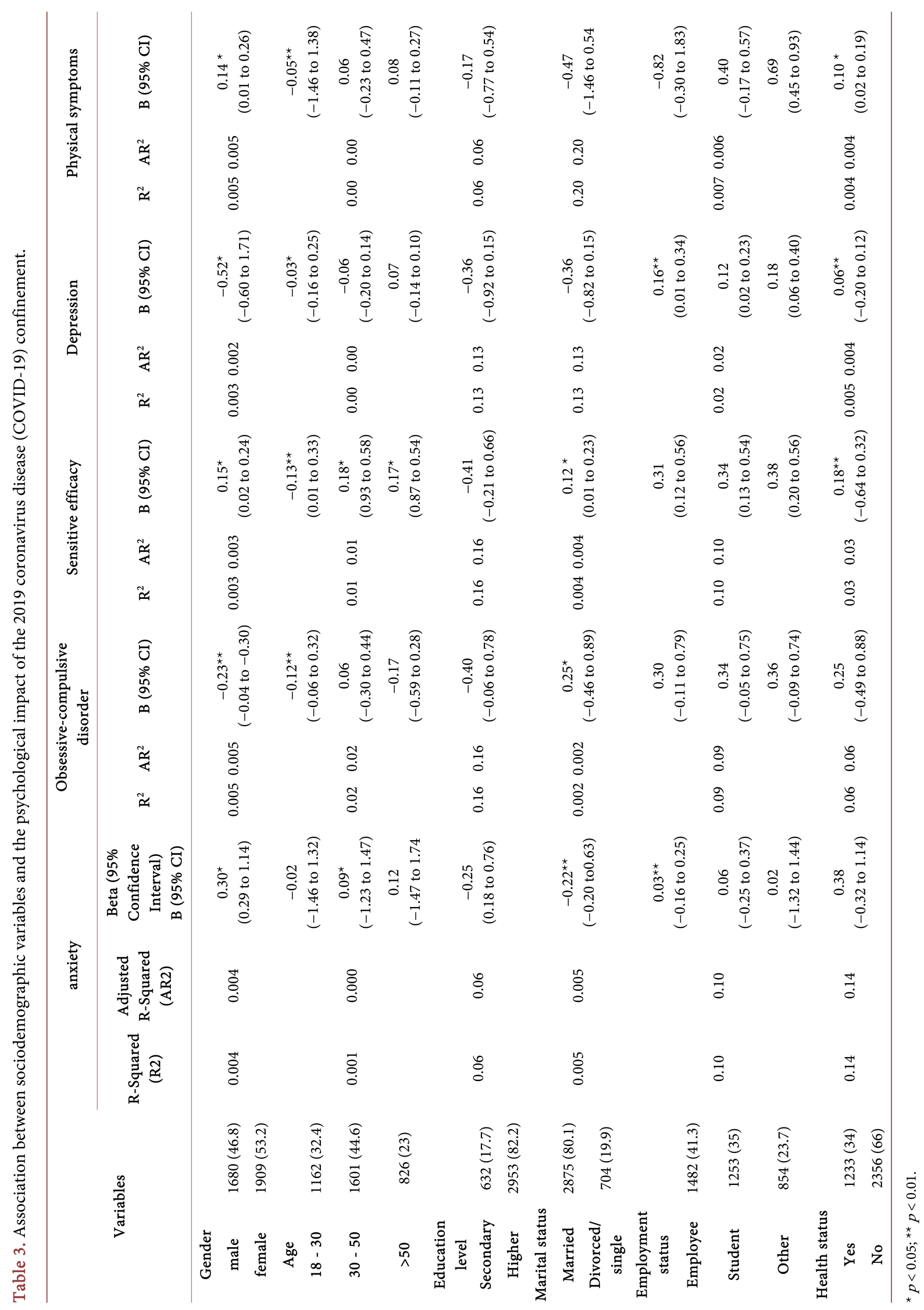




\section{Discussion}

It is quite obvious that health crises and epidemics cause an emotional shock for individuals, especially if they cannot accept what is occurring and do not adapt to the situation. In many cases, people who are emotionally fragile find themselves, psychologically speaking, paralyzed, giving rise to a feeling of helplessness, sadness, and anxiety. The world is currently experiencing an unpredictable situation due to the COVID-19 viruses causing uncertainty and fear. A person who may have simple flu symptoms such as coughing or simple throat irritation lives a situation of worry and wonders if he has COVID-19 or not. This situation has changed the way of life and the habits of individuals all over the world, starting with the obligation to wear a mask, regular washing of hands, up to social distancing measures. Because of this situation, people are currently living under constant stress and pressure for fear of getting infected with the virus.

This study is part of the understanding of the change in the rhythm of social life of the individual caused by confinement and to apprehend the consequences on the psychological health of the individual, in KSA. Our research hypotheses assume that given the social rhythm of the Saudi citizens who are very active and social life plays a considerable role in their lives, the containment caused by COVID-19 would have a negative effect on their social lives, thus causing psychological disorders such as anxiety and depression.

The results of this study show that there is a radical change in the social life style in Saudi Arabia, thus confirming the result of Wang et al. (2020) and Zhai et al. (2020) studies. This is explained by the fact that fear of contamination by the virus forced individuals to change their social habits, especially with the measures of confinement taken by the government (closure of shopping centres, restaurants, and cafes). This change was greater among women than men. This result makes sense given, as Brooks et al. (2020) explained, that women deal with problems with much less with anxiety than men and seek to talk about their problems and find solutions, unlike men, who prefer to emotionally escape these problems and focus on other things.

On the other hand, the results show that people aged from 30 to 50 , have radically changed their social habits and have shown far more respect for social sanitary measures. This result is explained by the fact that early information about COVID-19 indicated that this virus affects older people, who have chronic diseases much more than others Soladino et al., (2020). The same the same observation is noted for education level and marital status: married people have a significant change in their social life style.

Consistent with our hypothesis, the COVID-19 outbreak has radically changed the life style of Kingdome of Arabic Saudi citizens according to socio demographic variable. Accumulating evidences also point out the effect of COVID-19 outbreak in psychological life style in Saudi; specially for female, married people aged 30 to 50, and employee. These individuals have high levels of anxiety and depression than another participant. This result is explained by the fact that married persons and employee, have more responsibility towards their children 
and families than divorced/single persons, Zhai et al., (2020). This responsibility consists in providing for the needs of families, including purchases from the outside, thus inducing a feeling of fear and fear of contamination of loved ones.

This study also underlines the association between the change on social life and increased levels of depression and anxiety during confinement. We explained this result by the fact that each person has his own daily life's routine, meet problems, take new decision, and he search comfort and support in his family and friends every day and every moment. During confinement, he is deprived of this support, and as a result, he becomes more anxious, which leads to depression in extreme cases.

In general, this study finds that citizens of Kingdome of Arabic Saudi changed radically their social life style to adapt to new routines during confinement. This change significate that people become more anxious about their health and family, then about leisure and social activity. Some sociodemographic variables are significantly related to this change of social life style and psychological health than other variable. The results of this study contribute to the knowledge about the effect of quarantine in social life style and psychological health.

\section{Conclusion}

The present investigations revealed that home confinement was associated with a total change in the social lifestyles of the KSA, which caused a negative impact on social lives and psychological health, especially for married people, aged 30 to 50 years and for women. Despite this, quarantine showed that the Saudi community has a strong sense of responsibility as well as good awareness and respect for social distancing measures.

\section{Recommendations}

Our study suggests some important future research subjects to accurately identify the impact of COVID-19 on the social and psychological side of the person and of the community. We suggest that the health authority improve a strategy of psychological support for people to plan and fight effectively the negative effects of any future confinement.

\section{Funding}

This research was supported by the Deanship of Scientific Research, Taif University, and the Ministry of Education of Saudi Arabia under Grant 1-441-73.

\section{Ethics Approval}

The informed consent was obtained from all individual participants included in the study at the time of original data collection

\section{Conflicts of Interest}

The authors declare no conflicts of interest regarding the publication of this pa- 
per.

\section{References}

Abdel-Khalek, A. M. (2012). Convergent Validity of the Arabic Scale of Mental Health. Psychological Reports, 110, 16-24. https://doi.org/10.2466/03.09.PR0.110.1.16-24

Alfawaz, H. A., Wani, K., Aljumah, A. A., Aldisi, D., Ansari, M. G., Yakout, S. M., \& Al-Daghri, N. M. (2021). Psychological Well-Being during COVID-19 Lockdown: Insights from a Saudi State University's Academic Community. Journal of King Saud University-Science, 33, Article ID: 101262. https://doi.org/10.1016/j.jksus.2020.101262

Al-Fiqi, A. I., \& Mohammad, K. A.-F. (2020). [1] Psychological Problems Caused by Coronavirus COVIED-19 among a Sample of University Students in Egypt n.d. Journal of Education, University of Souhaj, 74, 1-43.

Ammar, A., Chtourou, H., Boukhris, O., Trabelsi, K., Masmoudi, L., Brach, M., Bouaziz, B., Bentlage, E., How, D., Ahmed, M., Mueller, P., Mueller, N., Hsouna, H., Aloui, A., Hammouda, O., Paineiras-Domingos, L., Braakman-Jansen, A., Wrede, C., Bastoni, S., \& Hoekelmann, A. (2020). COVID-19 Home Confinement Negatively Impacts Social Participation and Life Satisfaction: A Worldwide Multicenter Study. International Journal of Environmental Research and Public Health, 17, 6237.

Ammar, A., Trabelsi, K., Brach, M., Chtourou, H., Boukhris, O., Masmoudi, L., Bouaziz, B., Bentlage, E., How, D., Ahmed, M., Mueller, P., Mueller, N., Hammouda, O., Paineiras-Domingos, L., Braakman-Jansen, A., Wrede, C., Bastoni, S., Pernambuco, C., Mataruna, L., \& Hoekelmann, A. (2021). Effects of Home Confinement on Mental Health and Lifestyle Behaviours during the COVID-19 Outbreak: Insight from the ECLB-COVID19 Multicenter Study. Biology of Sport, 38, 9-21.

https://doi.org/10.5114/biolsport.2020.96857

Brooks, S. K., Webster, R. K., Smith, L. E., Woodland, L., Wessely, S., Greenberg, N., \& Rubin, G. J. (2020). The Psychological Impact of Quarantine and How to Reduce It: Rapid Review of the Evidence. The Lancet, 395, 912-920.

https://doi.org/10.1016/S0140-6736(20)30460-8

El-Gilany, A.-H. (2021). COVID-19 Caseness: An Epidemiologic Perspective. Journal of Infection and Public Health, 14, 61-65. https://doi.org/10.1016/j.jiph.2020.11.003

Lee, S. A., \& Crunk, E. A. (2020). Fear and Psychopathology during the COVID-19 Crisis: Neuroticism, Hypochondriasis, Reassurance-Seeking, and Coronaphobia as Fear Factors. OMEGA-Journal of Death and Dying, 0030222820949350. https://doi.org/10.1177/0030222820949350

Soladino, V., Algeri, D., \& Auriemma, V. (2020). The Psychological and Social Impact of Covid-19: New Perspectives of Well-Being. Frontiers in Psychology, 11, 2550. https://doi.org/10.3389/fpsyg.2020.577684

Torales, J., O’Higgins, M., Castaldelli-Maia, J. M., \& Ventriglio, A. (2020). The Outbreak of COVID-19 Coronavirus and Its Impact on Global Mental Health. International Journal of Social Psychiatry, 66, 317-320. https://doi.org/10.1177/0020764020915212

Wang, C., Horby, P. W., Hayden, F. G., \& Gao, G. F. (2020). A Novel Coronavirus Outbreak of Global Health Concern. The Lancet, 395, 470-473.

https://doi.org/10.1016/S0140-6736(20)30185-9

Wang, C., Pan, R., Wan, X., Tan, Y., Xu, L., Ho, C. S., \& Ho, R. C. (2020). Immediate Psychological Responses and Associated Factors during the Initial Stage of the 2019 Coronavirus Disease (COVID-19) Epidemic among the General Population in China. International Journal of Environmental Research and Public Health, 17, 1729. 
https://doi.org/10.3390/ijerph17051729

Zhai, Y., \& Du, X. (2020). Mental Health Care for International Chinese Students Affected by the COVID-19 Outbreak. The Lancet Psychiatry, 7, e22.

https://doi.org/10.1016/S2215-0366(20)30089-4 